\title{
sORF-Encoded Polypeptide SEP1 Is a Novel Virulence Factor of Phytophthora Pathogens
}

\author{
Nan Wang, ${ }^{1}$ Zhiyuan Yin, ${ }^{1}$ Weiwei Duan, ${ }^{2}$ Xiong Zhang, ${ }^{1}$ Lei Pi, ${ }^{1}$ Yifan Zhang, ${ }^{1}$ and Daolong Dou ${ }^{1,2,+}$ \\ ${ }^{1}$ College of Plant Protection, China Agricultural University, Beijing, China \\ ${ }^{2}$ College of Plant Protection, Nanjing Agricultural University, Nanjing, China
}

Accepted 25 October 2020.

\begin{abstract}
Diseases caused by the notorious Phytophthora spp. result in enormous economic losses to crops and forests. Increasing evidence suggests that small open reading frame-encoded polypeptides (SEPs) participate in environmental responses of animals, plants, and fungi. However, it remains largely unknown whether Phytophthora pathogens produce SEPs. Here, we systematically predicted and identified 96 SEP candidates in $P$. capsici. Among them, three may induce stable cell death in Nicotiana benthamiana. Phytophthora-specific and conserved SEP1 facilitated $P$. capsici infection. PcSEP1-induced cell death is BAK1 and SOBIR1 independent and is correlated with its virulence function. Finally, PcSEP1 may be targeted to the apoplast for carrying out its functions, for which the $\mathbf{C}$ terminus is indispensable. Together, our results demonstrated that SEP1 is a new virulence factor, and previously unknown SEPs may act as effector proteins in Phytophthora pathogens.
\end{abstract}

Keywords: apoplastic effector, cell death, oomycete effectors, Phytophthora capsici, small open reading frame

Phytophthora spp. are among the most notorious plant pathogens of oomycetes, which are highly destructive pathogens of crops and forests (Kamoun et al. 2015). For instance, the potato and tomato late blight caused by Phytophthora infestans (Nowicki et al. 2012), blight and fruit rot of vegetable crops caused by $P$. capsici (Granke et al. 2012), and soybean root and stem rot caused by $P$. sojae (Tyler 2007) are important threats to agricultural production and ecological systems. During infection and colonization of plants, these pathogens secrete a plethora of effector proteins to manipulate diverse processes of plant physiology and immunity by targeting key processes in immunity (Dou and Zhou 2012; He et al. 2020).

N. Wang and Z. Yin contributed equally to this work.

${ }^{\dagger}$ Corresponding author: D. Dou; ddou@ cau.edu.cn

Funding: This study was supported by the Fundamental Research Funds for the Central Universities (KYLH201703) and the National Natural Science Foundation of China (31625023 and 32072507).

*The $\boldsymbol{e}$-Xtra logo stands for "electronic extra" and indicates that supplementary tables and supplementary figures are published online.

The author(s) declare no conflict of interest.

Copyright $\odot 2021$ The Author(s). This is an open access article distributed under the CC BY-NC-ND 4.0 International license.
Generally, Phytophthora effectors are divided into two classes: apoplastic effectors and cytoplasmic effectors (Dou and Zhou 2012; Kamoun 2006; Wawra et al. 2012). Apoplastic effectors are secreted into the plant extracellular space, where effectors often require disulfide bonds between cysteine residues to maintain stability and activity (van den Burg et al. 2003; van den Hooven et al. 2001). A common feature of Phytophthora apoplastic effectors is that they are cysteine-rich, including PcF/SCR proteins (Chen et al. 2016; Nicastro et al. 2009), NLP toxins (Chen et al. 2018; Dong et al. 2012), Kazallike protease inhibitors EPI1 and EPI10 (Tian et al. 2004, 2005), and cystatin-like protease inhibitor EPIC (Tian et al. 2007). Cytoplasmic effectors are translocated to plant cells and consist of RxLR and CRN protein families with highly conserved N-terminal motifs (Wawra et al. 2012). RxLR and CRN effectors target diverse host processes to promote infection (He et al. 2020).

Small open reading frames (sORFs), which encode polypeptides shorter than 100 amino acids, are usually excluded from genome annotations. Indeed, recent studies have revealed that eukaryotic genomes contain numbers of possible sORFs, some of which are translated as sORF-encoded peptides (SEPs), which play pivotal roles in the development and adaptation to environmental stresses (Couso and Patraquim 2017; Hellens et al. 2016; Khitun et al. 2019; Ruiz-Orera and Albà 2019). For example, the 34-amino-acid peptide DWORF of humans can enhance sarco/endoplasmic reticulum $\mathrm{Ca}^{2+}$ adenosine triphosphatase activity in the muscle (Nelson et al. 2016). The mitochondrial 71-amino-acid peptide BRAWNIN is essential for vertebrate oxidative phosphorylation (Zhang et al. 2020). However, owing to the small size, low abundance, and high false positives of ab initio prediction, only a few SEPs have been characterized. Recently, systematic prediction and identification of SORFs or SEPs have been performed in several eukaryotic genomes. For example, 22 sORFs required for growth were identified in yeast (Kastenmayer et al. 2006), hundreds of putatively functional sORFs were identified in Drosophila spp. (Ladoukakis et al. 2011), and 49 Arabidopsis thaliana sORFs were found to be associated with morphogenesis (Hanada et al. 2013). Therefore, it is widely accepted that phytopathogens may also have many SEPs, some of which are probably involved in the interaction with host plants.

A few polypeptides secreted by phytopathogens have been confirmed to be key virulence factors in individual studies. For instance, the rapid alkalinization factor (RALF) peptide secreted by Fusarium oxysporum and many other phytopathogenic fungi increases infection by regulating the plant receptor-like kinase FERONIA (Masachis et al. 2016). RaxX, a tyrosine-sulfated peptide derived from Xanthomonas oryzae pv. oryzae, mimics the plant peptide hormone PSY to facilitate pathogen infection 
(Pruitt et al. 2017). As for Phytophthora pathogens, the apoplastic effector PcF toxin and SCR96 are shorter than 100 amino acids and are important virulence factors (Chen et al. 2016; Orsomando et al. 2001). Given that eukaryotic genomes often have thousands of sORFs, a plethora of pathogenesis-related sORF-encoded secreted peptides remain to be determined. To the best of our knowledge, genome-wide identification of SEPs from Phytophthora pathogens has not been reported.

$P$. capsici has a broad host range, including the model plants Nicotiana benthamiana and A. thaliana. Thus, it has emerged as a model Phytophthora pathogen to study Phytophthoraplant interactions (Lamour et al. 2012b; Wang et al. 2013). In this study, we aimed to systematically identify the secreted SEPs from 24 genomes of Phytophthora spp., and obtained 96 candidates that are conserved among different Phytophthora spp. whose encoding genes are upregulated during the infection of $A$. thaliana by $P$. capsici. Using transient expression assays in $N$. benthamiana, we demonstrated that PcSEP1, PcSEP19, and PcSEP36 induced stable cell death phenotypes. PcSEP1 is targeted to the apoplast during interaction and can induce cell death and promote plant susceptibility. Taken together, our results suggest that PcSEP1 is a novel sORF-encoded virulent factor in $P$. capsici, which may also be adapted to other, similar pathogens.

\section{RESULTS}

In silico selection of SEPs in $P$. capsici.

To identify sORF-encoded secreted polypeptides ranging from 25 to 99 residues, we first performed two parallel algorithms, Getorf (in the EMBOSS package) and MiPepid, because they may predict all of the ORFs and potential sORFs (Zhu and Gribskov 2019). Using the $P$. capsici genome (Lamour et al. 2012a) as a reference, both methods allowed us to obtain hundreds of thousands of sORF candidates (Fig. 1A). Among these, SEPs that contain N-terminal signal peptides (SPs) but lack the transmembrane domain were predicted by SignalP and TMHMM, respectively, which yielded thousands of SEP candidates (Fig. 1A). To exclude possible random sORFs, these SEPs were clustered with SEPs from 23 other Phytophthora spp. by SiLiX (Miele et al. 2011). In total, 1,161 P. capsici SEPs that were present in at least two Phytophthora spp. were selected for further analysis (Supplementary Table S1). Expression of SEP genes during $P$. capsici-A. thaliana interaction was examined using previously reported transcriptomes. These transcriptomes were sequenced from three mixed mRNA pools, including development, early infection, and late infection stages (Ma et al. 2018). Finally, 96 SEP candidates were selected for function analyses, including 90 upregulated during infection and 6 highly conserved in diverse Phytophthora pathogens (Fig. 1A and B). The detailed distribution of the 96 SEP homologs in 24 Phytophthora spp. is listed in Supplementary Table S2.

Effectors involved in the interaction with plants often exhibit a high level of polymorphism among different isolates (Yang et al. 2017). Thus, the polymorphisms of the 96 SEP candidates identified above were analyzed using the genomes of six other P. capsici isolates (Reyes-Tena et al. 2019). In total, only 26 SEPs were conserved among all isolates. The other 70 SEPs exhibited three types of variations, most of which were nonsynonymous point mutations, indicating that most of these SEP candidates were highly polymorphic (Fig. 1C). The sequence length of the 96 SEPs showed a balance distribution ranging from 30 to 99 amino acids (Fig. 1D). We further analyzed the cysteine content because it has been reported that a common feature of small secreted proteins of phytopathogens is that they are usually cysteine rich (Kamoun 2006). Consistently, 37 SEPs contained more than two cysteine residues (Fig. 1E). Function annotation of these
SEPs by searching the GenBank database with BLASTP showed that 78 SEPs had no significant homolog $(E$-value $<1 \mathrm{e}-3)$, and that 18 SEPs were homologous to hypothetical proteins without known functions (Supplementary Table S1).

\section{Three SEPs induce cell death in $N$. benthamiana.}

Small secreted proteins produced by phytopathogens during interaction often regulate plant immune responses (Masachis et al. 2016; Pruitt et al. 2017). To identify P. capsici SEPs that are involved in the interaction with plants, we transiently expressed SEPs in $N$. benthamiana. Because SEPs are polypeptides, fusion tags probably impair the functions. Thus, fulllength SEPs without a fusion tag were cloned into the pSuper vector. In total, 87 SEPs were successfully cloned, and the remaining 9 SEPs were cloned by gene synthesis. All 96 SEPs were expressed in $N$. benthamiana by agroinfiltration. At 3 days postinfiltration, three SEPs (PcSEP1, PcSEP19, and PcSEP36) induced stable cell death in $N$. benthamiana (Fig. 2A) while all others could not.

Apoplastic effector-induced cell death in N. benthamiana often requires the coreceptor BAK1 (Heese et al. 2007) or SOBIR1 (Liebrand et al. 2013). Tobacco rattle virus (TRV)-based virusinduced gene silencing was used to silence $B A K 1$ and SOBIRI to evaluate whether the aforementioned SEP-induced cell death requires $B A K 1$ or $S O B I R 1$. At 3 days postinfiltration, the positive control INF1-induced cell death was abolished in $B A K 1$ - and SOBIR1-silenced plants, whereas PcSEP1- and PcSEP19induced cell death were not affected (Fig. 2B). PcSEP36induced cell death was significantly impaired in $B A K 1$ - but not SOBIRl-silenced plants. Cell death was also confirmed by observing autofluorescent phenylpropanoid compounds caused by cell death under UV light (Fig. 2B). The expression levels of $B A K 1$ and SOBIRI in TRV-treated plants were verified by quantitative reverse-transcription PCR (qRT-PCR) analysis (Fig. 2C).

To further examine the role of SEPs during infection, PcSEP1, PcSEP19, and PcSEP36 were transiently expressed in $N$. benthamiana for $24 \mathrm{~h}$; then, $P$. capsici was inoculated at the infiltration sites. The results show that the average lesion diameters of PcSEP1- and PcSEP19-treated leaves were significantly larger than those of the negative control (Fig. 3A and C). The relative pathogen biomass in PcSEP1- and PcSEP19-treated leaves was also significantly higher than these of the negative control (Fig. 3B and D). This result reflects that transient expression of PcSEP1 and PcSEP19 promotes plant susceptibility to $P$. capsici. However, PcSEP36 had no effect on plant susceptibility (Fig. 3E and F). Collectively, these results suggest that PcSEP1 and PcSEP19 may function as virulent effectors, and PcSEP1 was selected for further studies.

\section{SEP1 is conserved and Phytophthora specific.}

The SEP1 alleles in six other $P$. capsici isolates showed polymorphisms, including nonsynonymous and indel mutations (Fig. 4A). To determine the phylogenetic distribution of PcSEP1 homologs in other species, we performed a BLASTP search of the GenBank database. Significant homologs $(E-$ value $<1$ e-5) were only found in the Phytophthora spp. tested, indicating that SEP1 is Phytophthora specific. Thus, PcSEP1 homologs of the other 23 Phytophthora spp. examined in this study were retrieved from the SEPs cluster result. In total, 32 PcSEP1 homologs from other Phytophthora spp. were identified, and each species had at least one homolog (Fig. 4A). SEP1 has also been expanded in several species. For instance, $P$. alni and $P$. cambivora have four and three homologs, respectively (Supplementary Fig. S1). All 33 SEP1 homologs were predicted to be secreted. Multiple sequence alignment showed that SEP1 is highly conserved among six $P$. capsici isolates from different host plants (Reyes-Tena et al. 2019) and 
different Phytophthora spp. (Fig. 4A). In contrast, homologs of SEP19 and SEP36 (Supplementary Fig. S2) from other Phytophthora spp. are variable in length, suggesting that they are not conserved.
To further assess whether the functions of SEP1 homologs are also conserved, three other SEP1 homologs (PsSEP1, PpSEP1, and PciSEP1) were cloned and transiently expressed in $N$. benthamiana. Similar to PcSEP1, these three candidates
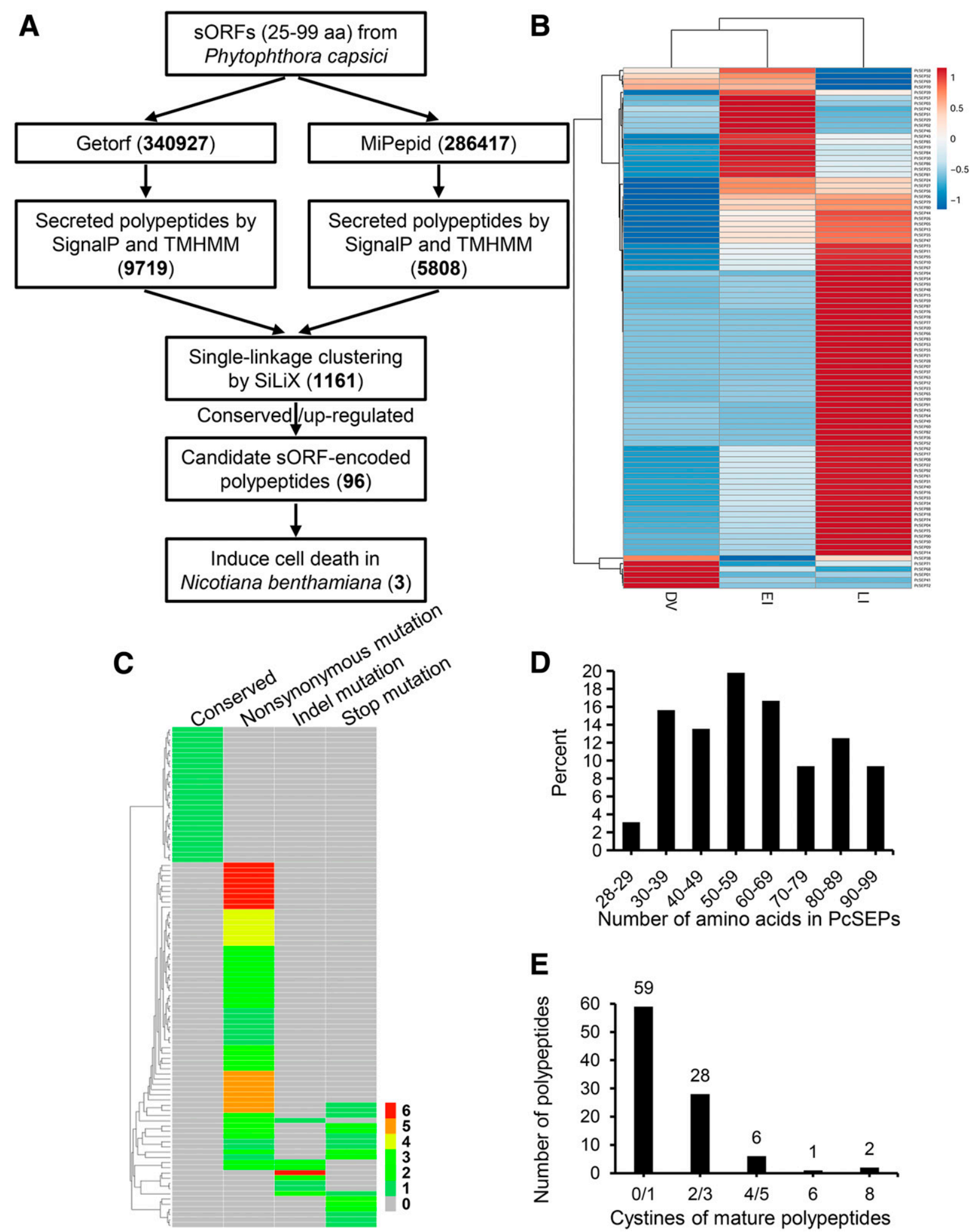

Fig. 1. Ab initio prediction of small open reading frame (sORF)-encoded polypeptides (SEPs) from Phytophthora capsici. A, Screening pipeline for SEPs from P. capsici. The number of the candidates obtained is shown in brackets. B, Heatmap showing the expression of 96 SEP candidates during infection of Arabidopsis thaliana. DV = development stage (mixture of mycelia, sporangia, swimming zoospores, cysts, and germinating cysts), EI = early infection stage (mixture of mycelia infection for 1, 2, and $4 \mathrm{~h}$ postinoculation [hpi]), and LI = late infection stage (mixture of mycelia infection for 8 and 48 hpi). Reads per kilobase million values were calculated by GFOLD from transcriptomes without biological replication and then subjected to generate the heatmap by web tool ClustVis (https://biit.cs.ut.ee/clustvis/). C, Polymorphism of 96 SEP candidates among six P. capsici isolates (Reyes-Tena et al. 2019). Numbers 1 to 6 indicate the number of isolates with polymorphism. D, Length distribution of 96 SEP candidates. E, Cysteine content distribution of 96 SEP candidates. 
also triggered cell death (Fig. 4B) and promoted N. benthamiana susceptibility to $P$. capsici (Fig. $4 \mathrm{C}$ to H). Thus, SEP1 has similar roles in different Phytophthora spp.

\section{N-terminal SP of PcSEP1 is required}

for cell-death-inducing and virulence activities.

To determine whether the N-terminal SP of PcSEP1 is functional, $\mathrm{SP}^{\mathrm{PcSEP} 1}$ was fused to the invertase gene and verified by the yeast signal trap assay system. The results showed that the fusion of $\mathrm{SP}^{\mathrm{PcSEP} 1}$ to invertase enabled the YTK12 yeast strain to grow on $1 \%$ yeast extract, $2 \%$ peptone, $2 \%$ raffinose, antimycin $\mathrm{A}$ at $8 \mu \mathrm{g} / \mathrm{liter}$, and $2 \%$ agar (YPRAA) medium, which was confirmed by the 2,3,5-triphenyltetrazolium chloride (TTC) reduction test (Supplementary Fig. S3). This result indicates that $\mathrm{SP}^{\mathrm{PcSEP} 1}$ resulted in the secretion of invertase. Then, the subcellular locations of mCherry-tagged PcSEP1 and PcSEP1 $1^{\triangle \mathrm{SP}}$ expressed in $N$. benthamiana were visualized with a confocal laser-scanning
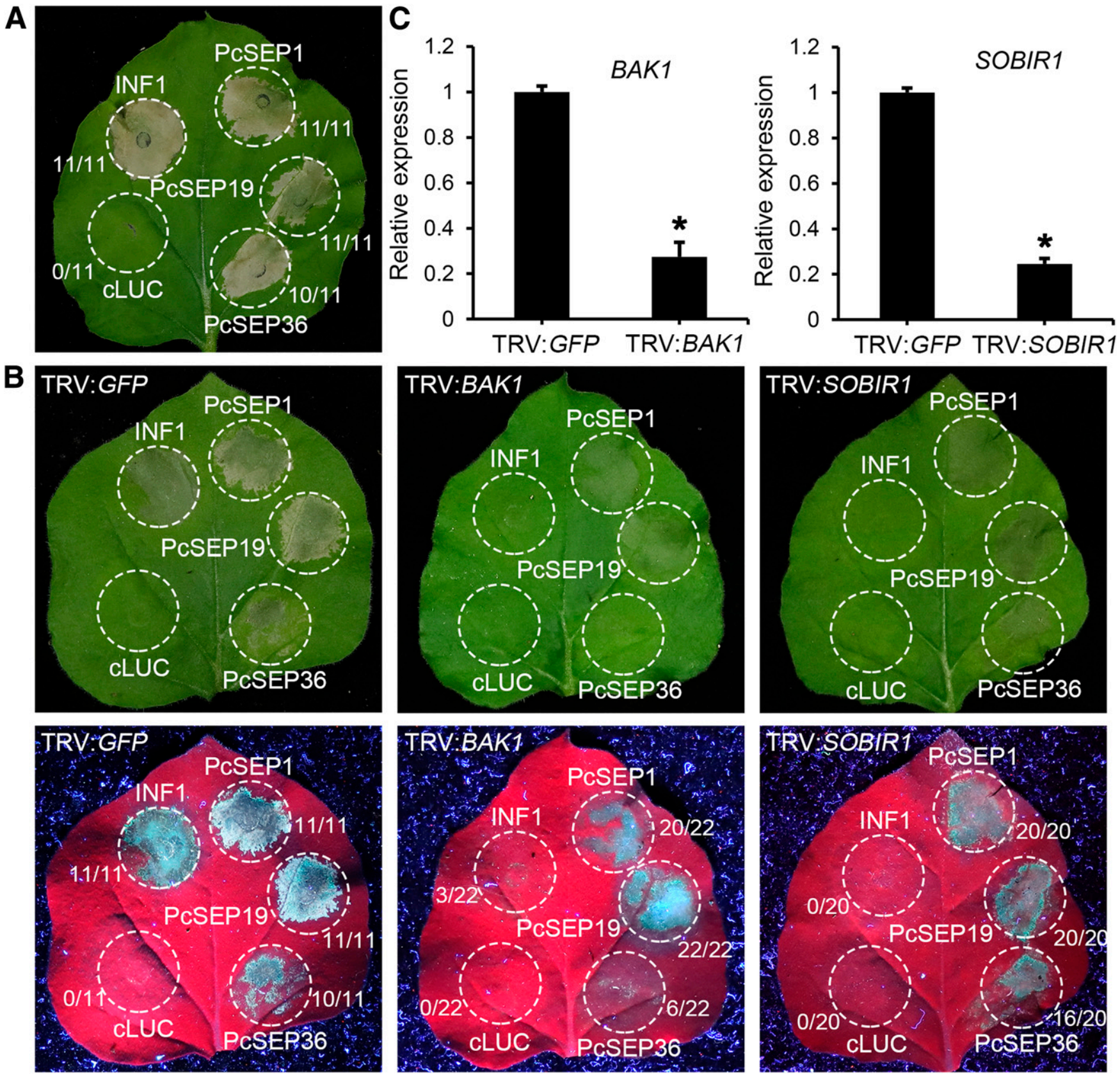

Fig. 2. Three small open reading frame-encoded polypeptides (SEPs) induce cell death in Nicotiana benthamiana. A, PcSEP1, PcSEP19, and PcSEP36 induced stable cell death in $N$. benthamiana after 3 days postinfiltration. INF1 and the firefly luciferase (LUC) fragment 398 to 550 (cLUC) were used as positive and negative controls, respectively. Ratios indicate the number of necrotic lesions out of the number of infiltration sites (for instance, $11 / 11$ indicates 11 necrotic lesions were observed out of 11 infiltration sites). B, Cell death induced by PcSEP1, PcSEP19, or PcSEP36 in BAK1- and SOBIR1-silenced N. benthamiana plants. Three weeks after plants were inoculated with tobacco rattle virus (TRV) constructs (TRV:GFP, TRV:BAK1, and TRV:SOBIR1), SEPs were transiently expressed in the silenced leaves. Photographs were taken at 3 days postinfiltration under white light (top) or UV light (bottom). TRV:GFP was used as a negative control. This assay was performed three times with six plants for each construct. C, Transcript levels of BAK1 and SOBIR1 genes in the silenced plants were measured by quantitative reverse-transcription PCR. Gene NbAct was used as an internal reference. Bars represent standard deviations from three independent biological replicates (* indicates $P<0.05$; Student's $t$ test). 
microscope. After plasmolyzing the plant cells, the PcSEP1mCherry signal was detected in the apoplast, whereas PcSEP1 ${ }^{\Delta S P}$-mCherry was only observed in the cell (Fig. 5A). To further confirm that PcSEP1 is secreted into the apoplast and induces cell death when expressed in $N$. benthamiana, $\mathrm{SP}^{\mathrm{PcSEP} 1}$ was deleted and expressed. PcSEP1 ${ }^{\triangle \mathrm{SP}}$ failed to trigger cell death, whereas full-length PcSEP1 triggered stable cell death (Fig. 5B). Immunoblot analysis confirmed that c-half luciferasetagged proteins were expressed normally in $N$. benthamiana (Fig. 5C). In addition, the average lesion diameters and relative pathogen biomass of PcSEP1 ${ }^{\triangle S P}$-treated leaves showed no significant difference from that of the negative control (Fig. 5D and E) but were significantly less than that of PcSEP1-treated leaves (Fig. $5 \mathrm{~F}$ and $\mathrm{G}$ ), indicating that PcSEP1 ${ }^{\triangle S P}$ could not promote plant susceptibility to $P$. capsici. These data indicate that PcSEP1 is most likely targeted to the apoplast to induce cell death and promote plant susceptibility.

\section{The C-terminal 10-amino-acid region is indispensable for SEP1 functions.}

Based on searches of the NCBI conserved domain database and Simple Modular Architecture Research Tool (Letunic and Bork 2018), no known domain was found in PcSEP1. Moreover, most regions of the PcSEP1 sequence are disordered, except for a 14-amino-acid $\alpha$-helix. To explore the key region for its function, a series of deletion mutants was generated and transiently expressed in $N$. benthamiana. Deletion of the 30 amino acids after SP or $\alpha$-helix did not affect the

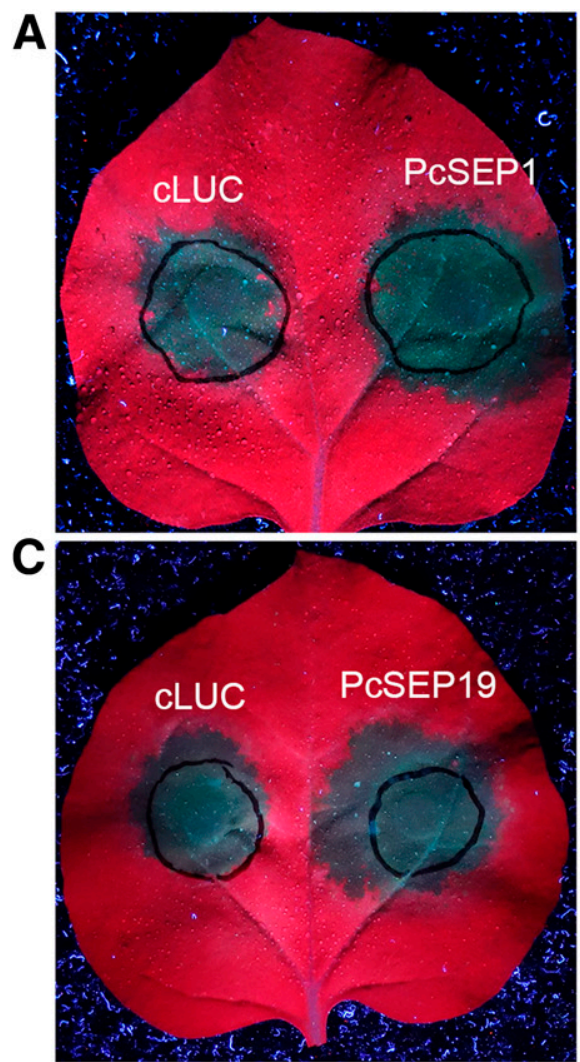

E

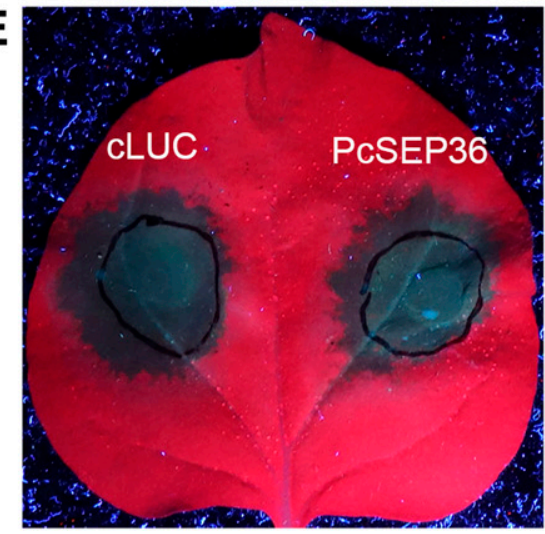

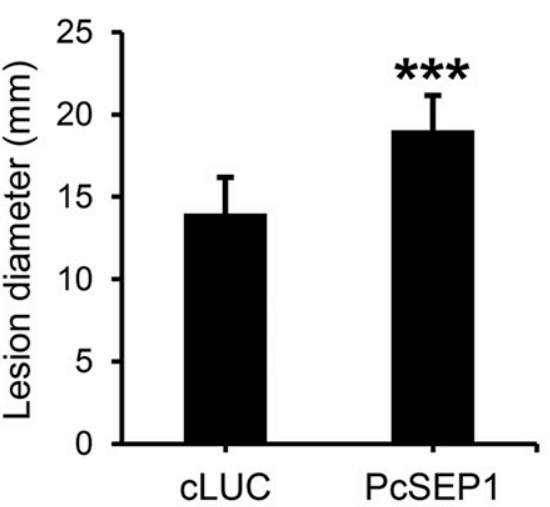
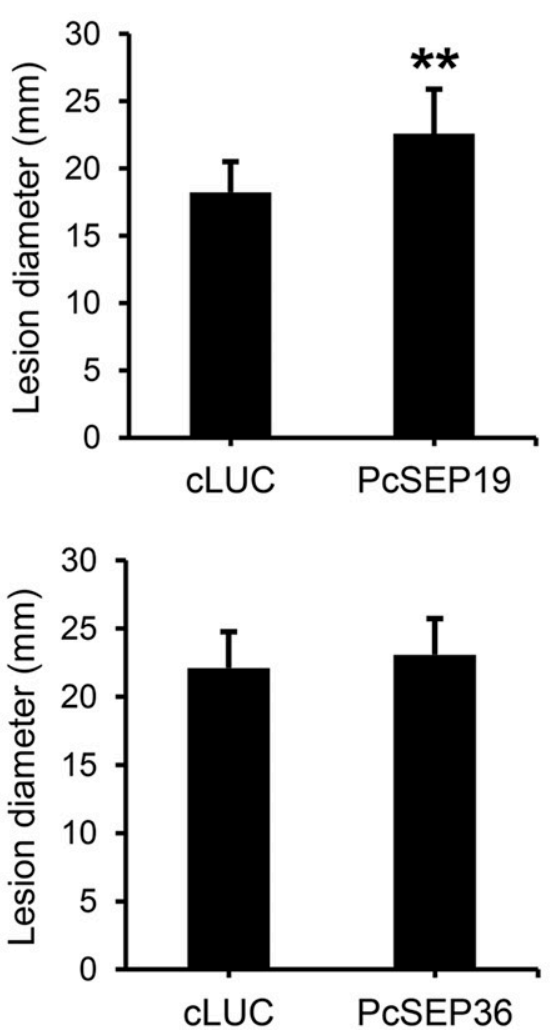

B

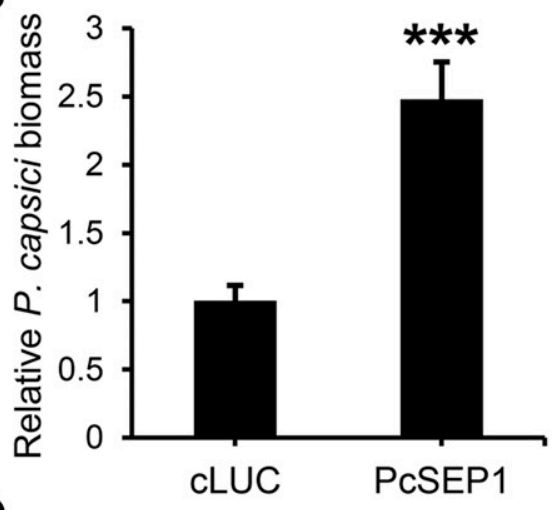

D

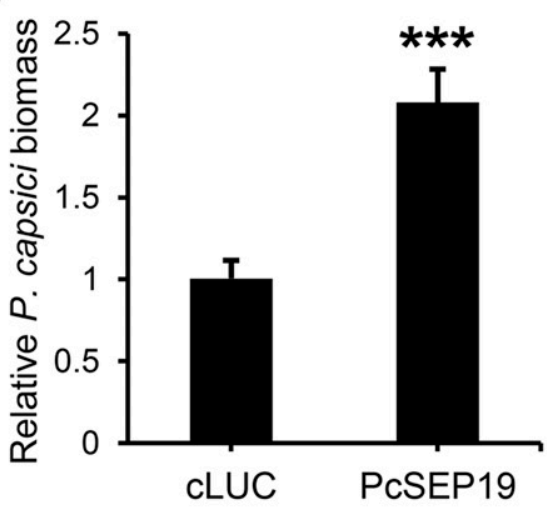

$\mathbf{F}$

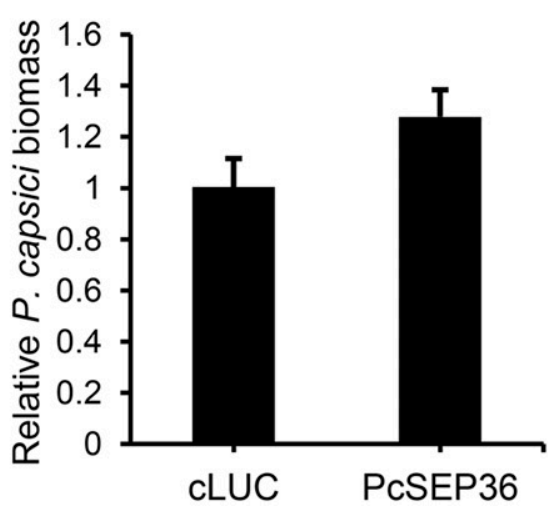

Fig. 3. Transient expression of PcSEP1 and PcSEP19 promote plant susceptibility to Phytophthora capsici. A, C, and E, Representative photographs of Nicotiana benthamiana leaves inoculated with $P$. capsici mycelial plugs and the associated average lesion diameters. $P$. capsici mycelial plugs were inoculated at the infiltration site after expressing luciferase (LUC) fragment 398 to 550 (cLUC) (as a control), PcSEP1 (A), PcSEP19 (C), or PcSEP36 (E) for 24 h. Photographs were taken under UV light at $36 \mathrm{~h}$ postinoculation. The hand-drawn black circles indicate the infiltration sites. Experiments were performed with at least three biological replicates with 10 leaves for each replicate. $\mathbf{B}, \mathbf{D}$, and $\mathbf{F}$, Relative biomass of $P$. capsici was measured by quantitative reversetranscription PCR at $36 \mathrm{~h}$ postinoculation. All of the statistical analyses in this figure were performed with a Student's $t$ test $(* *$ and $* * *$ indicate $P<0.01$ and 0.001 , respectively). Bars indicate \pm standard deviations. 

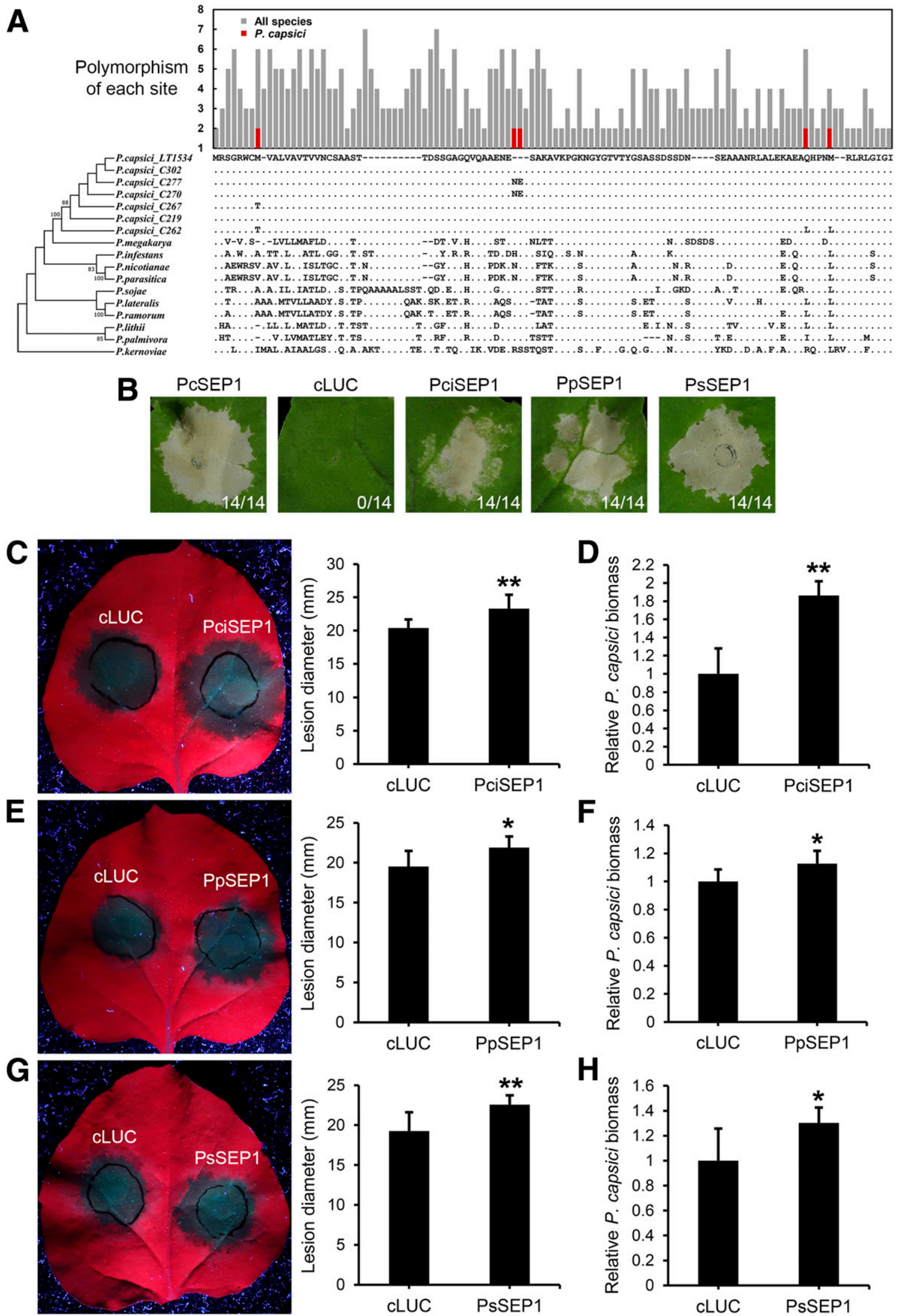

Fig. 4. Small open reading frame-encoded polypeptide 1 (SEP1) is conserved and Phytophthora specific. A, Polymorphism of PcSEP1 among Phytophthora capsici isolates and Phytophthora spp. B, SEP1 homologs also induce cell death in Nicotiana benthamiana. Ratios indicate the number of necrotic lesions out of the number of infiltration sites. PciSEP1, PpSEP1, and PsSEP1 indicate the SEP1 homologs from P. cinnamomi, P. parasitica, and $P$. sojae, respectively. C to $\mathbf{H}$, Transient expression of SEP1 homologs promotes plant susceptibility to $P$. capsici. $\mathbf{C}, \mathbf{E}$, and $\mathbf{G}$, Representative photographs and average lesion diameters. The hand-drawn black circles indicate the infiltration sites. D, F, and $\mathbf{H}$, Relative biomass of $P$. capsici was measured by quantitative reverse transcription PCR analysis. Experiments were performed with at least three biological replicates with 10 leaves for each replicate. All the statistical analyses in this figure were performed with a Student's $t$ test (* and ** indicate $P<0.05$ and 0.01 , respectively). Bars indicate \pm standard deviations. 
A
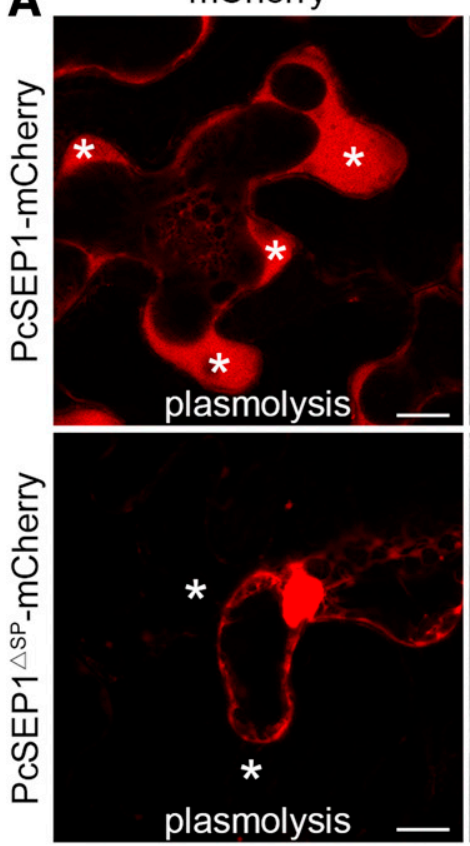

D

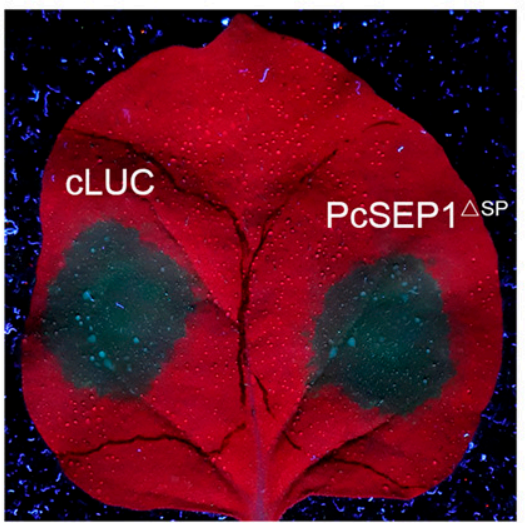

$\mathbf{F}$

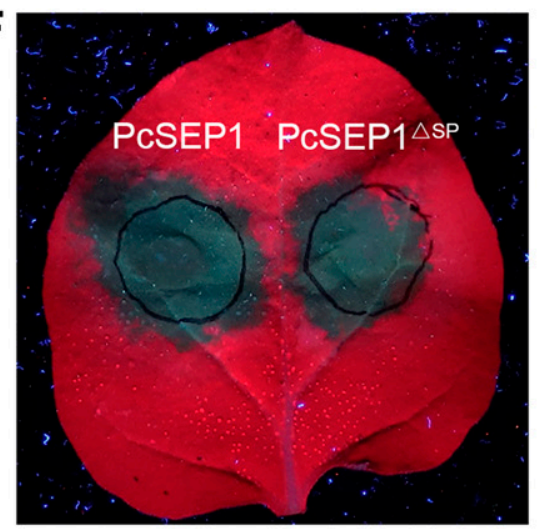

Bright field
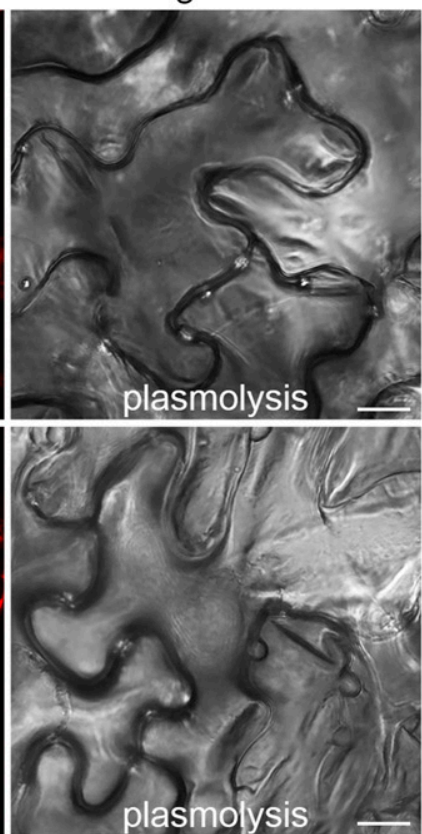

plasmolysis
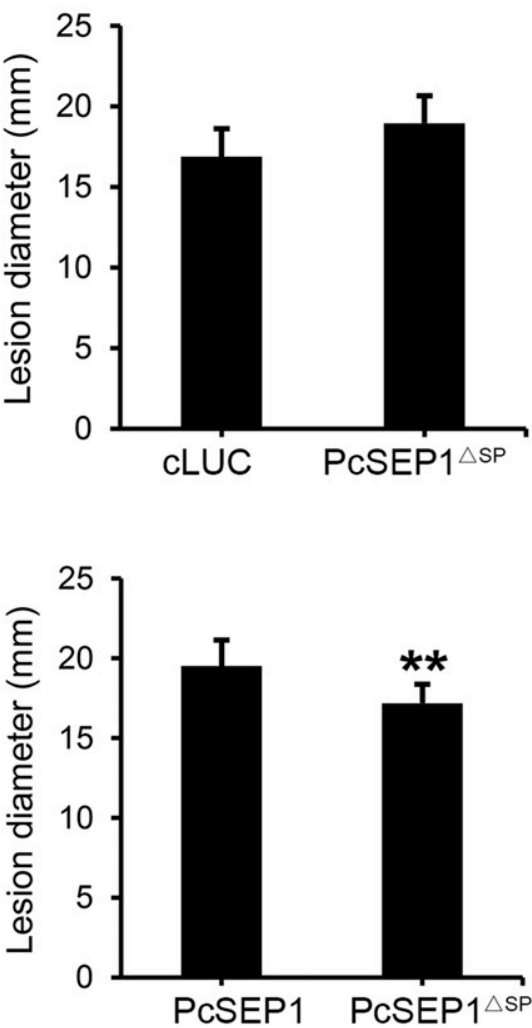

Merge

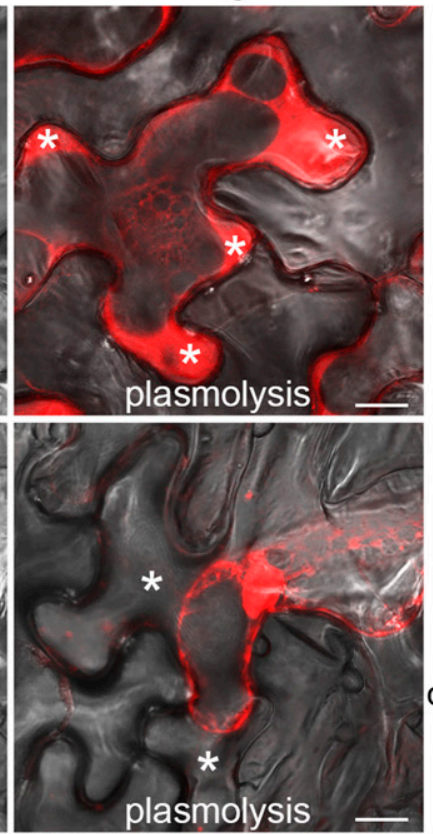

B

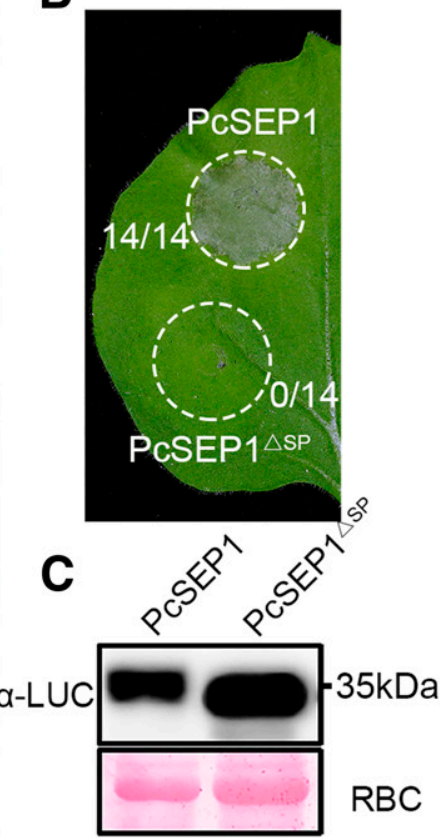

E

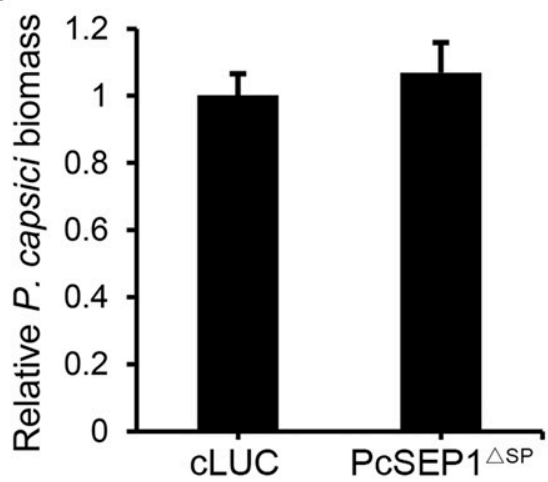

G

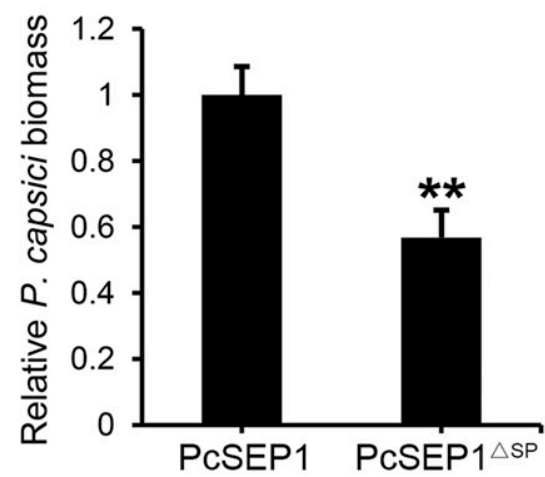

Fig. 5. N-terminal signal peptide (SP) of PcSEP1 is required for cell-death-inducing and virulence activities. A, Subcellular localization of PcSEP1-mCherry and PcSEP1 lacking SP mutant (PcSEP1 ${ }^{\triangle \mathrm{SP}}$-mCherry). Nicotiana benthamiana leaf epidermal cells expressing PcSEP1-mCherry and PcSEP1 ${ }^{\Delta \mathrm{SP}}$-mCherry were plasmolyzed in $30 \%$ glycerol for 10 to $15 \mathrm{~min}$ and visualized with a confocal laser-scanning microscope. Asterisks indicate the apoplastic space formed by the receding protoplast. Bars $=25 \mu \mathrm{m}$. B, PcSEP1 ${ }^{\Delta \mathrm{SP}}$ failed to induce cell death in $N$. benthamiana. Photographs were taken at 3 days postinfiltration. Ratios indicate the number of necrotic lesions out of the number of infiltration sites. C, Western blot showing that all of the proteins in B were expressed normally. Rubisco (RBC) was used as the loading control. D to G, PcSEP1 ${ }^{\Delta \mathrm{SP}}$ failed to promote plant susceptibility to Phytophthora capsici. Representative photographs of $N$. benthamiana leaves inoculated with P. capsici mycelial plugs after expressing D, luciferase (LUC) fragment 398 to 550 (cLUC) and PcSEP1 ${ }^{\Delta \mathrm{SP}}$ or $\mathbf{F}$, PcSEP1 and PcSEP1 ${ }^{\Delta S P}$ at $24 \mathrm{~h}$. Diameters of the lesions were measured $36 \mathrm{~h}$ postinoculation. Photographs were taken at $36 \mathrm{~h}$ after inoculation. The handdrawn black circles indicate the infiltration sites. $\mathbf{E}$ and $\mathbf{G}$, Relative biomass of $P$. capsici was determined by quantitative reverse transcription PCR at $36 \mathrm{~h}$ postinoculation. All the statistical analyses in this figure were performed with a Student's t test (** indicate $P<0.01)$. Bars indicate \pm standard deviations. 
A

PCSEP1
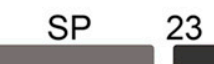

death

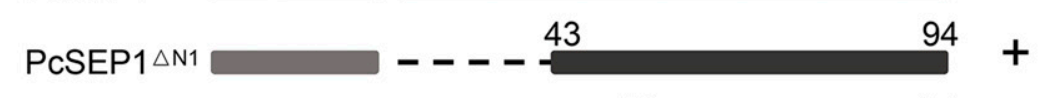

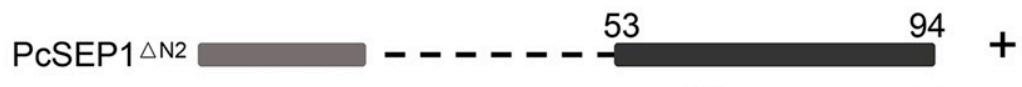
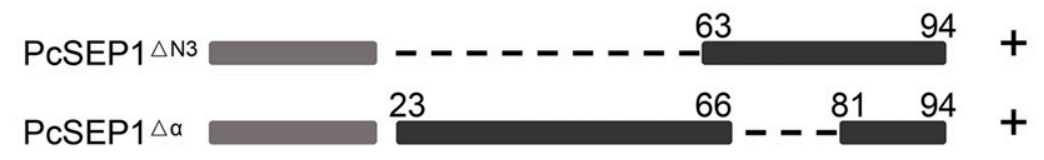

PcSEP1 $\triangle \mathrm{C} 1$ 23 83

$\operatorname{PCSEP} 1 \triangle \mathrm{C} 2$
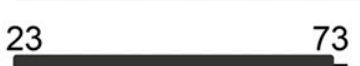

\section{B}
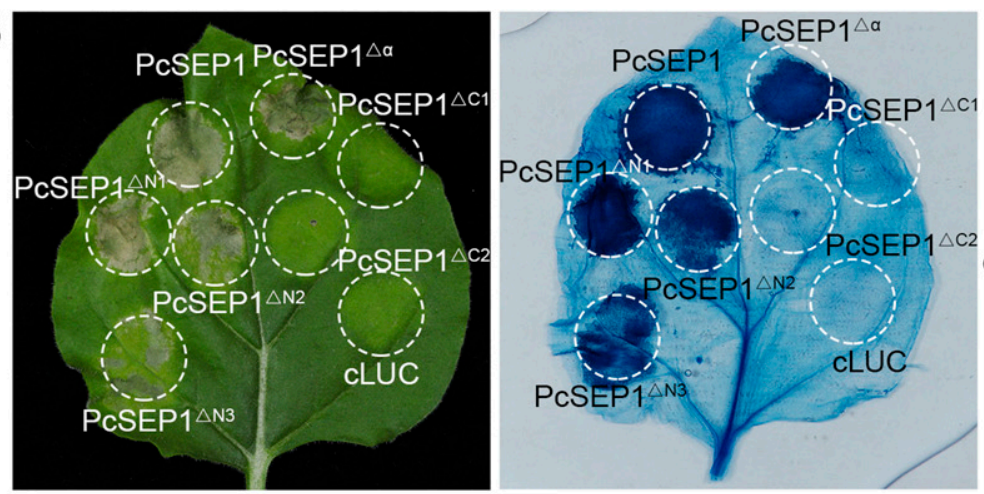

D
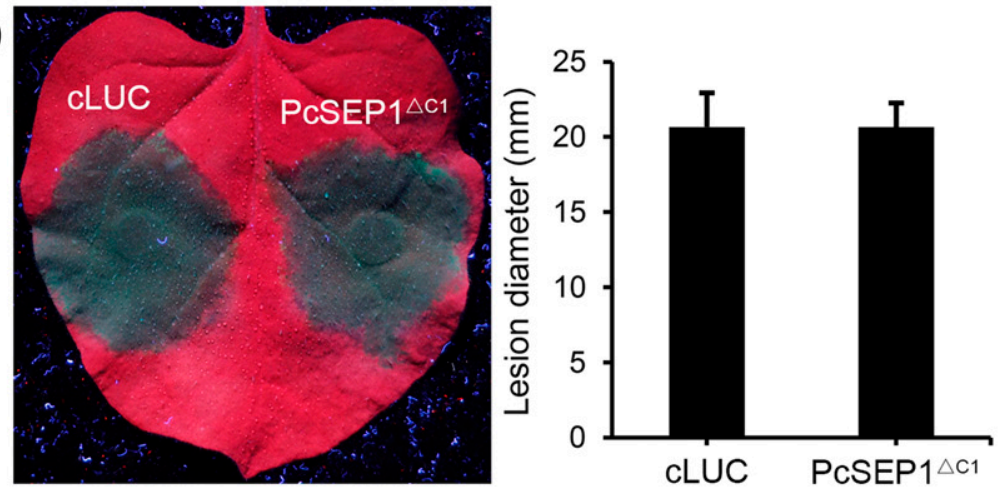

E

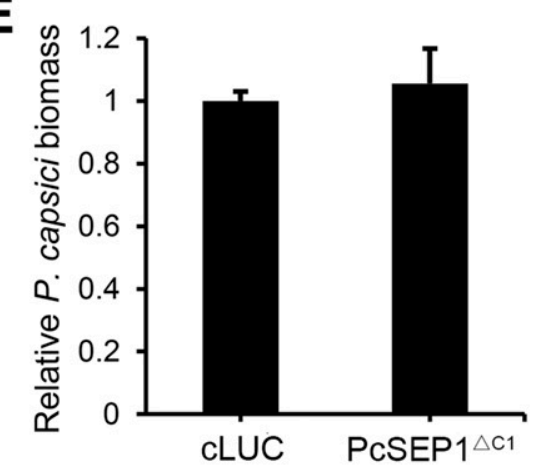

$\mathbf{F}$
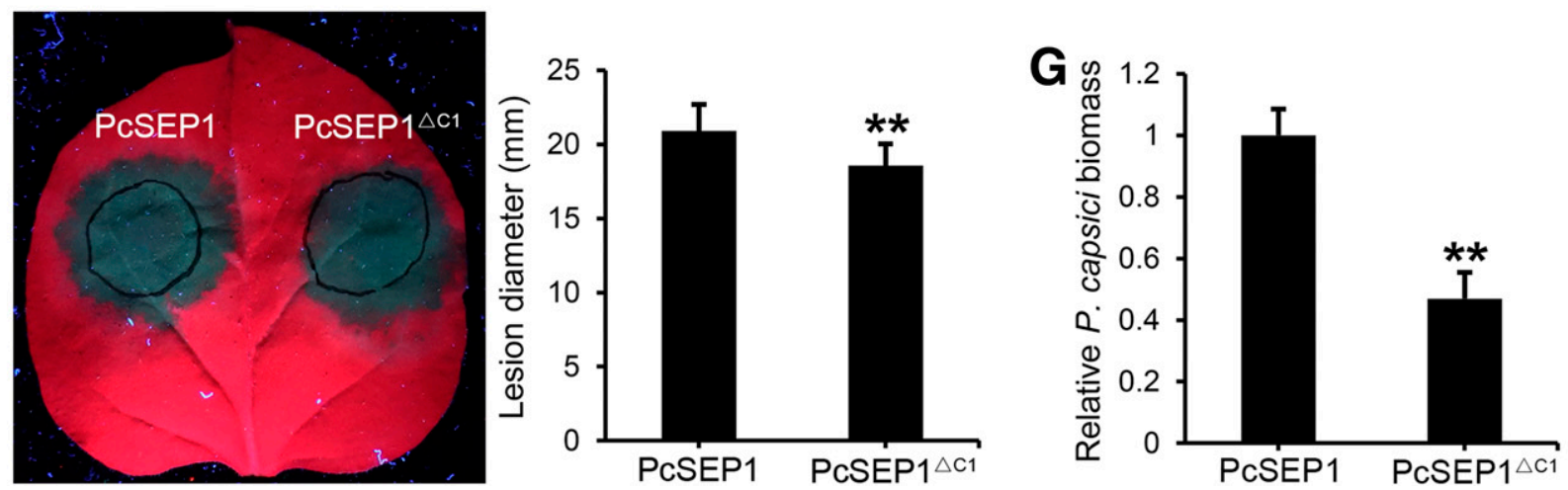

Fig. 6. The $\mathrm{C}$ terminus is indispensable for small open reading frame-encoded polypeptide 1 (SEP1) functions. A, Diagram of PcSEP1 deletion mutants. B, Deletion of the $\mathrm{C}$ terminus failed to induce cell death, confirmed by trypan blue staining. Luciferase (LUC) fragment 398 to 550 (cLUC) was used as the negative control. C, Western blot showing that all of the proteins in B were expressed normally. Rubisco (RBC) was used as the loading control. D to G, Mutant without the $\mathrm{C}$ terminus failed to promote plant susceptibility to Phytophthora capsici. Representative photographs of Nicotiana benthamiana leaves inoculated with $P$. capsici mycelial plugs after expressing D, cLUC and PcSEP1 ${ }^{\Delta \mathrm{Cl} 1}$ or F, PcSEP1 and PcSEP1 ${ }^{\Delta \mathrm{C} 1}$ at $24 \mathrm{~h}$. Diameters of the lesions were measured $36 \mathrm{~h}$ after inoculation. Photographs were taken at $36 \mathrm{~h}$ after inoculation. The hand-drawn black circles indicate the infiltration sites. E and $\mathbf{G}$, Relative biomass of $P$. capsici was determined by quantitative reverse transcription PCR at $36 \mathrm{~h}$ postinoculation. All the statistical analyses in this figure were performed with a Student's $t$ test (** indicate $P<0.01)$. Bars indicate \pm standard deviations. 
cell-death-inducing activity, whereas $\operatorname{PcSEP}^{\Delta \mathrm{N} 3}$-induced cell death was impaired but not abolished (Fig. 6A and 6B). The deletion of the C-terminal 10 amino acids completely abolished cell-death-inducing activity (Fig. 6A and B). The cell death phenotypes were confirmed by trypan blue staining assay (Fig. $6 \mathrm{~B})$, and all of the proteins were properly expressed by immunoblot analysis (Fig. 6C). To further determine whether the $\mathrm{C}$ terminus is required for virulence, $\mathrm{PcSEP} 1^{\Delta \mathrm{C} 1}$ was expressed in $N$. benthamiana; then, infiltration sites were inoculated with $P$. capsici. The results showed that the expression of PcSEP1 ${ }^{\Delta \mathrm{C} 1}$ failed to enlarge the lesions caused by $P$. capsici (Fig. 6D). The relative biomass of $P$. capsici in $\mathrm{PcSEP} 1{ }^{\mathrm{C} 1}$-treated regions was not higher than that of the negative control (Fig. 6E). However, the average lesion diameters and relative pathogen biomass of PcSEP1 ${ }^{\Delta C 1}$-treated leaves were significantly less than that of PcSEP1-treated leaves (Fig. 6F and $\mathrm{G}$ ). These findings suggest that the $\mathrm{C}$ terminus is indispensable for PcSEP1 functions and that PcSEP1-induced cell death is correlated with its virulence.

\section{DISCUSSION}

Increasing evidence suggests that SEPs participate in the development and environmental responses of animals (Ladoukakis et al. 2011; Zhang et al. 2020), plants (Hanada et al. 2013), and fungi (Kastenmayer et al. 2006). For example, maize $\mathrm{Zm908p} 11$ functions as a profilin ligand and is required for pollen tube growth (Dong et al. 2013). However, SEPs hidden in the genomes of Phytophthora pathogens remain undetermined. Moreover, identifying functional SEPs from countless random sORF-deduced polypeptides is challenging. In this study, we performed ab initio prediction of secreted SEPs from Phytophthora pathogens to screen SEP candidates involved in virulence. During coevolution with plants, effector proteins secreted by pathogens undergo natural selection, which makes the effector highly polymorphic (Asai et al. 2018; Huang et al. 2019; Yang et al. 2017). Consistent with previous findings, most of the SEP candidates identified in $P$. capsici were polymorphic, suggesting that they are promising effector candidates. To identify potentially functional SEPs in $P$. capsici, the conserved and upregulated SEPs were selected for high-throughput expression in $N$. benthamiana. Three SEPs were shown to induce stable cell death in $N$. benthamiana, among which PcSEP1 is a novel virulence factor of $P$. capsici and is highly conserved in the Phytophthora spp. Our results demonstrated that secreted SEPs of Phytophthora are functional during infection of the host plant.

The known effectors of Phytophthora are divided into distinct categories based on the feature of sequences. For example, RxLR and CRN effectors have conserved N-terminal motifs, and most apoplastic effectors are cysteine rich, albeit with different cysteine numbers and patterns (Dou and Zhou 2012; Kamoun 2006; Wawra et al. 2012). However, neither cysteine residue nor RxLR and CRN motifs were found in PcSEP1. Moreover, PcSEP1 has no known conserved domain, SEP1 homologs are restricted in the Phytophthora genus, and all of the 24 species examined have at least one homolog. The sequence of SEP1 homologs is highly conserved in Phytophthora spp., and several of them also induced cell death in $N$. benthamiana and promoted infection by $P$. capsici when transiently expressed. These findings suggest that SEP1 is a novel type of Phytophthora effector.

Some apoplastic effectors induce cell death because they are recognized by plant cell surface-localized pattern recognition receptors. $P$. sojae XEG1 is a glycoside hydrolase that can degrade plant cell walls during infection but is also recognized as a pathogen-associated molecular pattern (PAMP) by plant receptor-like protein RXEG1 (Ma et al. 2015; Y. Wang et al.
2018). Similarly, $P$. infestans INF1 is an elicitin that can bind sterols and other lipids but is recognized as a PAMP (Derevnina et al. 2016). Generally, PAMP-induced cell death depends on the coreceptor BAK1 or SOBIR1 (Liebrand et al. 2014). In this study, PcSEP1- and PcSEP19-induced cell death are both BAK1 and SOBIR1 independent, whereas BAK1 is required for PcSEP36-induced cell death, suggesting that a potential leucine-rich repeat receptor-like kinase probably regulates the perception of PcSEP36. Moreover, transient expression of PcSEP1 did not induce plant resistance to $P$. capsici. Several deletion mutants that could not induce cell death also failed to promote plant susceptibility, suggesting that PcSEP1-induced cell death is correlated with its virulence activity. These findings suggest that PcSEP1 is a new virulence factor conserved in Phytophthora pathogens. Given that the fungal sORF-encoded peptide RALF facilitates infection by regulating plant receptorlike kinase FERONIA (Masachis et al. 2016), it is possible that PcSEP1 also targets a plant pattern receptor to regulate plant susceptibility. The detailed mechanism of its virulence function will be explored in the future.

In summary, we systematically identified and characterized sORF-encoded polypeptides in P. capsici, a model Phytophthora pathogen. Three SEPs can induce stable cell death in $N$. benthamiana, among which the Phytophthora-specific and conserved SEP1 is a new virulence factor. Our findings will facilitate the understanding of the mechanism of Phytophthora pathogens during infection.

\section{MATERIALS AND METHODS}

\section{Prediction of sORFs in $P$. capsica.}

To identify sORF candidates in $P$. capsici, we first obtained all of the ORFs (75 to $300 \mathrm{bp}$ ) from genome assemblies (Lamour et al. 2012a). Moreover, the machine-learning-based micropeptide identification tool MiPepid was also used to predict sORFs (Zhu and Gribskov 2019). The deduced polypeptides of these ORFs were subjected to prediction of secreted polypeptides using SignalP v4.1 and TMHMM v2.0, as described previously (Ai et al. 2020). Only sORFs that overlapped in the two methods were selected for further analysis. To identify conserved sORFs among Phytophthora spp., we predicted sORFs from 23 other Phytophthora genomes. All of the secreted polypeptides were clustered by SiLiX (Miele et al. 2011). sORFs present in at least two genomes were selected for expression analysis. Detailed information on the predicted sORFs is summarized in Supplementary Tables S1 and S2. The raw reads of $P$. capsici transcriptomes during infection in plants (Ma et al. 2018) were remapped to the genome by hisat2 (Kim et al. 2019), and the upregulated sORFs were identified by GFOLD (Feng et al. 2012). Finally, the sORF candidates were obtained for further function analyses. The primers used for this study are listed in Supplementary Tables S3 and S4.

\section{Plant growth condition and Agrobacterium tumefaciens infiltration assays.}

$N$. benthamiana plants were grown in a climate chamber at $25^{\circ} \mathrm{C}$ with a 16-h photoperiod and $60 \%$ relative humidity. For transient expression of sORFs in N. benthamiana, all 96 candidates were amplified from the genomic DNA of $P$. capsici strain LT263 and cloned into the binary vector pSuper. The primers used for this study are listed in Supplementary Table S3. The constructs were then transformed into Agrobacterium tumefaciens strain GV3101. A. tumefaciens cultures were pelleted, resuspended in infiltration buffer $(10 \mathrm{mM}$ morpholineethanesulfonic acid, $10 \mathrm{mM} \mathrm{MgCl}$, and $200 \mathrm{mM}$ acetosyringone) to a final concentration of optical density at $600 \mathrm{~nm}\left(\mathrm{OD}_{600}\right)=0.5$, 
and infiltrated into 5-week-old $N$. benthamiana leaves, as described previously (Dou et al. 2008).

For TRV silencing of BAK1 or SOBIR1, A. tumefaciens harboring TRV:BAK1 or TRV:SOBIR1 was mixed 1:1 with A. tumefaciens carrying TRV1 and infiltrated into true leaves of five-leaf-stage $N$. benthamiana seedlings. TRV:GFP was used as a negative control. Three weeks after agroinfiltration, plants were used to express sORFs. The efficiency of gene silencing was examined by qRT-PCR.

\section{$P$. capsici infection assay.}

To investigate the role of sORF during $P$. capsici infection, $N$. benthamiana leaves transiently expressing sORF for $24 \mathrm{~h}$ were detached and then inoculated on the infiltration site with a fresh mycelial plug of $P$. capsici. Inoculated leaves were kept in a plastic box with high humidity, and lesion diameters were measured at $36 \mathrm{~h}$ postinoculation. A $25-\mathrm{mm}$-diameter region of the inoculated leaf covering the lesion was collected for genomic DNA extraction to calculate the relative pathogen DNA biomass. Relative biomass was examined by qPCR using PcAct and $N b A c t$ as reference genes. The results represented the ratio of $P$. capsici to $N$. benthamiana genomic DNA, and statistical significance was determined using a Student's $t$ test.

\section{Yeast secretion trap assay.}

Functional validation of the predicted signal sequence of PcSEP1 was conducted using a yeast signal sequence trap system, as described previously (Jacobs et al. 1997). Briefly, we PCR amplified the predicted signal sequence of PcSEP1 (the first 22 amino acids) into the pSUC2T7M13ORI (pSUC2) vector, which contains a truncated invertase gene (SUC2) lacking the SP. The pSUC2-SP ${ }^{\text {PcSEP1 }}$ and pSUC2-SP ${ }^{\text {Avrlb }}$ were used as positive controls and pSUC2-SP ${ }^{\mathrm{Mg} 87}$, as a negative control, was transformed into invertase-deletion yeast strain YTK12. Yeast cultivation and transformation were performed as described previously (N. Wang et al. 2018). The positive colonies were incubated overnight at $30^{\circ} \mathrm{C}$ with shaking $(220 \mathrm{rpm})$ to an $\mathrm{OD}_{600}=1$. The yeast cultures were then grown on plates of yeast extract at $10 \mathrm{~g} \mathrm{liter}^{-1}$, peptone at $20 \mathrm{~g} \mathrm{liter}^{-1}$, glucose at $20 \mathrm{~g} \mathrm{liter}^{-1}$, and agar at $20 \mathrm{~g} \mathrm{liter}^{-1}$; plates of $0.67 \%$ yeast nitrogen base, $0.075 \%$ tryptophan drop-out supplement, $2 \%$ sucrose, $0.1 \%$ glucose, and $2 \%$ agar; and YPRAA plates. To determine invertase enzymatic activity, $400 \mu \mathrm{l}$ of yeast culture was pipetted into glass test tubes containing $200 \mathrm{ml}$ of $5 \%$ sucrose solution and $267 \mu \mathrm{l}$ of $1 \%$ TTC solution (dissolved in $1 \mathrm{M}$ $\mathrm{NaOH}$ ). After incubating at $35^{\circ} \mathrm{C}$ for $30 \mathrm{~min}$, a colorimetric change was observed. Primers used for the yeast secretion trap assay are listed in Supplementary Table S4.

\section{Trypan blue staining.}

$N$. benthamiana leaves were detached and incubated in trypan blue solution $(0.4 \%$ trypan blue in the mixture of lactic acidphenol-glycerol-water-ethanol $=1: 1: 1: 1: 6[\mathrm{vol} / \mathrm{vol} / \mathrm{vol} / \mathrm{vol} / \mathrm{vol}])$ at $100^{\circ} \mathrm{C}$ for $5 \mathrm{~min}$, followed by incubation in the dark at room temperature for $24 \mathrm{~h}$. Leaves were destained by incubating in chloral hydrate at $2.5 \mathrm{~g} / \mathrm{ml}$ and $37^{\circ} \mathrm{C}$ for $24 \mathrm{~h}$.

\section{Immunoblotting.}

Total proteins of $N$. benthamiana leaves were extracted using RIPA lysis buffer (150 mM NaCl, $5 \mathrm{mM}$ EDTA [pH 8.0], $50 \mathrm{mM}$ Tris $[\mathrm{pH} 8.0], 1 \% \mathrm{NP}-40,0.5 \%$ sodium deoxycholate, and $0.1 \%$ sodium dodecyl sulfate). Western blots were developed with antiluciferase primary monoclonal antibodies (Sigma-Aldrich), as described previously (Fan et al. 2018).

\section{Subcellular localization.}

PcSEP1 and PcSEP1 lacking SP mutants $\left(\mathrm{PcSEP}^{\triangle \mathrm{SP}}\right)$ were introduced into the pSuper-mCherry vector, then transiently expressed in $N$. benthamiana leaves by agroinfiltration for $48 \mathrm{~h}$. Plasmolysis was performed by immersing pieces of leaves in $30 \%$ glycerol for 10 to $15 \mathrm{~min}$, then imaged using a Leica DMI8 confocal laser-scanning microscope. mCherry fluorescent protein was excited at $552 \mathrm{~nm}$ and detected at 580 to $630 \mathrm{~nm}$.

\section{LITERATURE CITED}

Ai, G., Yang, K., Ye, W., Tian, Y., Du, Y., Zhu, H., Li, T., Xia, Q., Shen, D., Peng, H., Jing, M., Xia, A., and Dou, D. 2020. Prediction and characterization of RXLR effectors in Pythium species. Mol. PlantMicrobe Interact. 33:1046-1058.

Asai, S., Furzer, O. J., Cevik, V., Kim, D. S., Ishaque, N., Goritschnig, S., Staskawicz, B. J., Shirasu, K., and Jones, J. D. G. 2018. A downy mildew effector evades recognition by polymorphism of expression and subcellular localization. Nat. Commun. 9:5192.

Chen, X. R., Huang, S. X., Zhang, Y., Sheng, G. L., Li, Y. P., and Zhu, F. 2018. Identification and functional analysis of the NLP-encoding genes from the phytopathogenic oomycete Phytophthora capsici. Mol. Genet. Genomics 293:931-943.

Chen, X. R., Li, Y. P., Li, Q. Y., Xing, Y. P., Liu, B. B., Tong, Y. H., and Xu, J. Y. 2016. SCR96, a small cysteine-rich secretory protein of Phytophthora cactorum, can trigger cell death in the Solanaceae and is important for pathogenicity and oxidative stress tolerance. Mol. Plant Pathol. 17:577-587.

Couso, J. P., and Patraquim, P. 2017. Classification and function of small open reading frames. Nat. Rev. Mol. Cell Biol. 18:575-589.

Derevnina, L., Dagdas, Y. F., De la Concepcion, J. C., Bialas, A., Kellner, R., Petre, B., Domazakis, E., Du, J., Wu, C. H., Lin, X., Aguilera-Galvez, C., Cruz-Mireles, N., Vleeshouwers, V. G., and Kamoun, S. 2016. Nine things to know about elicitins. New Phytol. 212:888-895.

Dong, S., Kong, G., Qutob, D., Yu, X., Tang, J., Kang, J., Dai, T., Wang, H., Gijzen, M., and Wang, Y. 2012. The NLP toxin family in Phytophthora sojae includes rapidly evolving groups that lack necrosis-inducing activity. Mol. Plant-Microbe Interact. 25:896-909.

Dong, X., Wang, D., Liu, P., Li, C., Zhao, Q., Zhu, D., and Yu, J. 2013. Zm908p11, encoded by a short open reading frame (sORF) gene, functions in pollen tube growth as a profilin ligand in maize. J. Exp. Bot. 64:2359-2372.

Dou, D., Kale, S. D., Wang, X., Chen, Y., Wang, Q., Wang, X., Jiang, R. H., Arredondo, F. D., Anderson, R. G., Thakur, P. B., McDowell, J. M., Wang, Y., and Tyler, B. M. 2008. Conserved C-terminal motifs required for avirulence and suppression of cell death by Phytophthora sojae effector Avr1b. Plant Cell 20:1118-1133.

Dou, D., and Zhou, J.-M. 2012. Phytopathogen effectors subverting host immunity: Different foes, similar battleground. Cell Host Microbe 12: 484-495.

Fan, G., Yang, Y., Li, T., Lu, W., Du, Y., Qiang, X., Wen, Q., and Shan, W. 2018. A Phytophthora capsici RXLR effector targets and inhibits a plant PPIase to suppress endoplasmic reticulum-mediated immunity. Mol. Plant 11:1067-1083.

Feng, J., Meyer, C. A., Wang, Q., Liu, J. S., Shirley Liu, X., and Zhang, Y. 2012. GFOLD: A generalized fold change for ranking differentially expressed genes from RNA-seq data. Bioinformatics 28:2782-2788.

Granke, L. L., Quesada-Ocampo, L., Lamour, K., and Hausbeck, M. K. 2012. Advances in research on Phytophthora capsici on vegetable crops in the United States. Plant Dis. 96:1588-1600.

Hanada, K., Higuchi-Takeuchi, M., Okamoto, M., Yoshizumi, T., Shimizu, M., Nakaminami, K., Nishi, R., Ohashi, C., Iida, K., Tanaka, M., Horii, Y., Kawashima, M., Matsui, K., Toyoda, T., Shinozaki, K., Seki, M., and Matsui, M. 2013. Small open reading frames associated with morphogenesis are hidden in plant genomes. Proc. Natl. Acad. Sci. U.S.A. 110:2395-2400.

He, Q., McLellan, H., Boevink, P. C., and Birch, P. R. 2020. All roads lead to susceptibility: The many modes-of-action of fungal and oomycete intracellular effectors. Plant Commun. 1:100050. doi:

Heese, A., Hann, D. R., Gimenez-Ibanez, S., Jones, A. M., He, K., Li, J., Schroeder, J. I., Peck, S. C., and Rathjen, J. P. 2007. The receptor-like kinase SERK3/BAK1 is a central regulator of innate immunity in plants. Proc. Natl. Acad. Sci. U.S.A. 104:12217-12222.

Hellens, R. P., Brown, C. M., Chisnall, M. A. W., Waterhouse, P. M., and MacKnight, R. C. 2016. The emerging world of small ORFs. Trends Plant Sci. 21:317-328.

Huang, J., Chen, L., Lu, X., Peng, Q., Zhang, Y., Yang, J., Zhang, B. Y., Yang, B., Waletich, J. R., Yin, W., Zheng, X., Wang, Y., and Dong, S. 2019. Natural allelic variations provide insights into host adaptation of Phytophthora avirulence effector PsAvr3c. New Phytol. 221:1010-1022. 
Jacobs, K. A., Collins-Racie, L. A., Colbert, M., Duckett, M., Golden-Fleet, M., Kelleher, K., Kriz, R., LaVallie, E. R., Merberg, D., Spaulding, V., Stover, J., Williamson, M. J., and McCoy, J. M. 1997. A genetic selection for isolating cDNAs encoding secreted proteins. Gene 198:289-296.

Kamoun, S. 2006. A catalogue of the effector secretome of plant pathogenic oomycetes. Annu. Rev. Phytopathol. 44:41-60.

Kamoun, S., Furzer, O., Jones, J. D., Judelson, H. S., Ali, G. S., Dalio, R. J., Roy, S. G., Schena, L., Zambounis, A., Panabières, F., Cahill, D., Ruocco, M., Figueiredo, A., Chen, X. R., Hulvey, J., Stam, R., Lamour, K., Gijzen, M., Tyler, B. M., Grünwald, N. J., Mukhtar, M. S., Tomé, D. F., Tör, M., Van Den Ackerveken, G., McDowell, J., Daayf, F., Fry, W. E., Lindqvist-Kreuze, H., Meijer, H. J., Petre, B., Ristaino, J., Yoshida, K., Birch, P. R., and Govers, F. 2015. The Top 10 oomycete pathogens in molecular plant pathology. Mol. Plant Pathol. 16:413-434.

Kastenmayer, J. P., Ni, L., Chu, A., Kitchen, L. E., Au, W. C., Yang, H., Carter, C. D., Wheeler, D., Davis, R. W., Boeke, J. D., Snyder, M. A., and Basrai, M. A. 2006. Functional genomics of genes with small open reading frames (sORFs) in S. cerevisiae. Genome Res. 16:365-373.

Khitun, A., Ness, T. J., and Slavoff, S. A. 2019. Small open reading frames and cellular stress responses. Mol. Omics 15:108-116.

Kim, D., Paggi, J. M., Park, C., Bennett, C., and Salzberg, S. L. 2019. Graph-based genome alignment and genotyping with HISAT2 and HISAT-genotype. Nat. Biotechnol. 37:907-915.

Ladoukakis, E., Pereira, V., Magny, E. G., Eyre-Walker, A., and Couso, J. P. 2011. Hundreds of putatively functional small open reading frames in Drosophila. Genome Biol. 12:R118.

Lamour, K. H., Mudge, J., Gobena, D., Hurtado-Gonzales, O. P., Schmutz, J., Kuo, A., Miller, N. A., Rice, B. J., Raffaele, S., Cano, L. M., Bharti, A. K., Donahoo, R. S., Finley, S., Huitema, E., Hulvey, J., Platt, D., Salamov, A., Savidor, A., Sharma, R., Stam, R., Storey, D., Thines, M., Win, J., Haas, B. J., Dinwiddie, D. L., Jenkins, J., Knight, J. R., Affourtit, J. P., Han, C. S., Chertkov, O., Lindquist, E. A., Detter, C., Grigoriev, I. V., Kamoun, S., and Kingsmore, S. F. 2012a. Genome sequencing and mapping reveal loss of heterozygosity as a mechanism for rapid adaptation in the vegetable pathogen Phytophthora capsici. Mol. PlantMicrobe Interact. 25:1350-1360.

Lamour, K. H., Stam, R., Jupe, J., and Huitema, E. 2012b. The oomycete broad-host-range pathogen Phytophthora capsici. Mol. Plant Pathol. 13: 329-337.

Letunic, I., and Bork, P. 2018. 20 years of the SMART protein domain annotation resource. Nucleic Acids Res. 46:D493-D496.

Liebrand, T. W., van den Berg, G. C., Zhang, Z., Smit, P., Cordewener, J. H., America, A. H., Sklenar, J., Jones, A. M., Tameling, W. I., Robatzek, S., Thomma, B. P. H. J., and Joosten, M. H. A. J. 2013. Receptor-like kinase SOBIR1/EVR interacts with receptor-like proteins in plant immunity against fungal infection. Proc. Natl. Acad. Sci. U.S.A. 110:10010-10015.

Liebrand, T. W., van den Burg, H. A., and Joosten, M. H. 2014. Two for all: Receptor-associated kinases SOBIR1 and BAK1. Trends Plant Sci. 19: 123-132.

Ma, H., Shen, D., Wu, Y., Xu, H., and Dou, D. 2018. RNA-seq for comparative transcript profiling of Phytophthora capsici during its interaction with Arabidopsis thaliana. Physiol. Mol. Plant Pathol. 102: 193-199.

Ma, Z., Song, T., Zhu, L., Ye, W., Wang, Y., Shao, Y., Dong, S., Zhang, Z., Dou, D., Zheng, X., Tyler, B. M., and Wang, Y. 2015. A Phytophthora sojae glycoside hydrolase 12 protein is a major virulence factor during soybean infection and is recognized as a PAMP. Plant Cell 27: 2057-2072.

Masachis, S., Segorbe, D., Turrà, D., Leon-Ruiz, M., Fürst, U., El Ghalid, M., Leonard, G., López-Berges, M. S., Richards, T. A., Felix, G., and Di Pietro, A. 2016. A fungal pathogen secretes plant alkalinizing peptides to increase infection. Nat. Microbiol. 1:16043.

Miele, V., Penel, S., and Duret, L. 2011. Ultra-fast sequence clustering from similarity networks with SiLiX. BMC Bioinf. 12:116.

Nelson, B. R., Makarewich, C. A., Anderson, D. M., Winders, B. R., Troupes, C. D., Wu, F., Reese, A. L., McAnally, J. R., Chen, X., Kavalali, E. T., Cannon, S. C., Houser, S. R., Bassel-Duby, R., and Olson, E. N. 2016. A peptide encoded by a transcript annotated as long noncoding RNA enhances SERCA activity in muscle. Science 351:271-275.

Nicastro, G., Orsomando, G., Ferrari, E., Manconi, L., Desario, F., Amici, A., Naso, A., Carpaneto, A., Pertinhez, T. A., Ruggieri, S., and Spisni, A. 2009. Solution structure of the phytotoxic protein PcF: The first characterized member of the Phytophthora PcF toxin family. Protein Sci. 18:1786-1791.
Nowicki, M., Foolad, M. R., Nowakowska, M., and Kozik, E. U. 2012. Potato and tomato late blight caused by Phytophthora infestans: An overview of pathology and resistance breeding. Plant Dis. 96:4-17.

Orsomando, G., Lorenzi, M., Raffaelli, N., Dalla Rizza, M., Mezzetti, B., and Ruggieri, S. 2001. Phytotoxic protein PcF, purification, characterization, and cDNA sequencing of a novel hydroxyproline-containing factor secreted by the strawberry pathogen Phytophthora cactorum. J. Biol. Chem. 276:21578-21584.

Pruitt, R. N., Joe, A., Zhang, W., Feng, W., Stewart, V., Schwessinger, B., Dinneny, J. R., and Ronald, P. C. 2017. A microbially derived tyrosinesulfated peptide mimics a plant peptide hormone. New Phytol. 215: 725-736.

Reyes-Tena, A., Huguet-Tapia, J. C., Lamour, K. H., Goss, E. M., Rodríguez-Alvarado, G., Vázquez-Marrufo, G., Santillán-Mendoza, R., and Fernández-Pavía, S. P. 2019. Genome sequence data of six isolates of Phytophthora capsici from Mexico. Mol. Plant-Microbe Interact. 32: 1267-1269.

Ruiz-Orera, J., and Albà, M. M. 2019. Translation of small open reading frames: Roles in regulation and evolutionary innovation. Trends Genet. 35:186-198.

Tian, M., Benedetti, B., and Kamoun, S. 2005. A Second Kazal-like protease inhibitor from Phytophthora infestans inhibits and interacts with the apoplastic pathogenesis-related protease P69B of tomato. Plant Physiol. 138:1785-1793.

Tian, M., Huitema, E., Da Cunha, L., Torto-Alalibo, T., and Kamoun, S. 2004. A Kazal-like extracellular serine protease inhibitor from Phytophthora infestans targets the tomato pathogenesis-related protease P69B. J. Biol. Chem. 279:26370-26377.

Tian, M., Win, J., Song, J., van der Hoorn, R., van der Knaap, E., and Kamoun, S. 2007. A Phytophthora infestans cystatin-like protein targets a novel tomato papain-like apoplastic protease. Plant Physiol. 143: 364-377.

Tyler, B. M. 2007. Phytophthora sojae: Root rot pathogen of soybean and model oomycete. Mol. Plant Pathol. 8:1-8.

van den Burg, H. A., Westerink, N., Francoijs, K. J., Roth, R., Woestenenk, E., Boeren, S., de Wit, P. J., Joosten, M. H., and Vervoort, J. 2003. Natural disulfide bond-disrupted mutants of AVR4 of the tomato pathogen Cladosporium fulvum are sensitive to proteolysis, circumvent Cf-4-mediated resistance, but retain their chitin binding ability. J. Biol. Chem. 278:27340-27346.

van den Hooven, H. W., van den Burg, H. A., Vossen, P., Boeren, S., de Wit, P. J., and Vervoort, J. 2001. Disulfide bond structure of the AVR9 elicitor of the fungal tomato pathogen Cladosporium fulvum: Evidence for a cystine knot. Biochemistry 40:3458-3466.

Wang, N., Yang, H., Yin, Z., Liu, W., Sun, L., and Wu, Y. 2018. Phytoplasma effector SWP1 induces witches' broom symptom by destabilizing the TCP transcription factor BRANCHED1. Mol. Plant Pathol. 19:2623-2634.

Wang, Y., Bouwmeester, K., van de Mortel, J. E., Shan, W., and Govers, F. 2013. A novel Arabidopsis-oomycete pathosystem: Differential interactions with Phytophthora capsici reveal a role for camalexin, indole glucosinolates and salicylic acid in defence. Plant Cell Environ. 36: 1192-1203.

Wang, Y., Xu, Y., Sun, Y., Wang, H., Qi, J., Wan, B., Ye, W., Lin, Y., Shao, Y., Dong, S., Tyler, B. M., and Wang, Y. 2018. Leucine-rich repeat receptor-like gene screen reveals that Nicotiana RXEG1 regulates glycoside hydrolase 12 MAMP detection. Nat. Commun. 9:594.

Wawra, S., Belmonte, R., Löbach, L., Saraiva, M., Willems, A., and van West, P. 2012. Secretion, delivery and function of oomycete effector proteins. Curr. Opin. Microbiol. 15:685-691.

Yang, B., Wang, Q., Jing, M., Guo, B., Wu, J., Wang, H., Wang, Y., Lin, L., Wang, Y., Ye, W., Dong, S., and Wang, Y. 2017. Distinct regions of the Phytophthora essential effector Avh238 determine its function in cell death activation and plant immunity suppression. New Phytol. 214: 361-375.

Zhang, S., Reljić, B., Liang, C., Kerouanton, B., Francisco, J. C., Peh, J. H., Mary, C., Jagannathan, N. S., Olexiouk, V., Tang, C., Fidelito, G., Nama, S., Cheng, R. K., Wee, C. L., Wang, L. C., Duek Roggli, P., Sampath, P., Lane, L., Petretto, E., Sobota, R. M., Jesuthasan, S., Tucker-Kellogg, L., Reversade, B., Menschaert, G., Sun, L., Stroud, D. A., and Ho, L. 2020. Mitochondrial peptide BRAWNIN is essential for vertebrate respiratory complex III assembly. Nat. Commun. 11:1312.

Zhu, M., and Gribskov, M. 2019. MiPepid: MicroPeptide identification tool using machine learning. BMC Bioinf. 20:559. 